\title{
Ocular motor behaviour of monozygotic twins with tyrosinase negative oculocutaneous albinism
}

\author{
R V Abadi, E Pascal
}

\begin{abstract}
The involuntary nystagmus movements of 16year-old monozygotic twins with tyrosinase negative oculocutaneous albinism were examined. On primary gaze both girls exhibited bilateral conjugate horizontal nystagmus, a jerk with extended foveation waveform, and similar frequencies $(2.0 \mathrm{~Hz}: 1.9 \mathrm{~Hz})$, although the fast phases were in opposite directions. The mean amplitudes differed markedly $\left(6 \cdot 8^{\circ}: 3 \cdot 7^{\circ}\right)$, as did the position of the null zones $\left(+20^{\circ}\right.$ to $+30^{\circ}:-25^{\circ}$ to $\left.-35^{\circ}\right)$ and the widths of the neutral zones $\left(-25^{\circ}\right.$ to $+20^{\circ}$ : $-25^{\circ}$ to $\left.-35^{\circ}\right)$. Since the twins have identical genotypes these differences must have arisen from other sources.
\end{abstract}

(Br f Ophthalmol 1994; 78: 349-352)

Tyrosinase negative oculocutaneous albinism (TNOCA) is one of at least 11 disorders with the phenotypic characteristics of oculocutaneous albinism. The complete lack of tyrosinase synthesis results in a total absence of detectable melanin pigment. Thus, affected individuals have snow white hair, pale pink skin that burns on exposure to sunlight, diaphanous grey or pale blue irides, amelanotic fundi, hypoplastic foveae, and nystagmus. ${ }^{1-6}$

The prevalence of TNOCA in the United States is approximately 1 in 39000 for white people and 1 in 28000 in Afro-Americans. ${ }^{7}$ Similar incidences have been reported in the United Kingdom. ${ }^{8}$

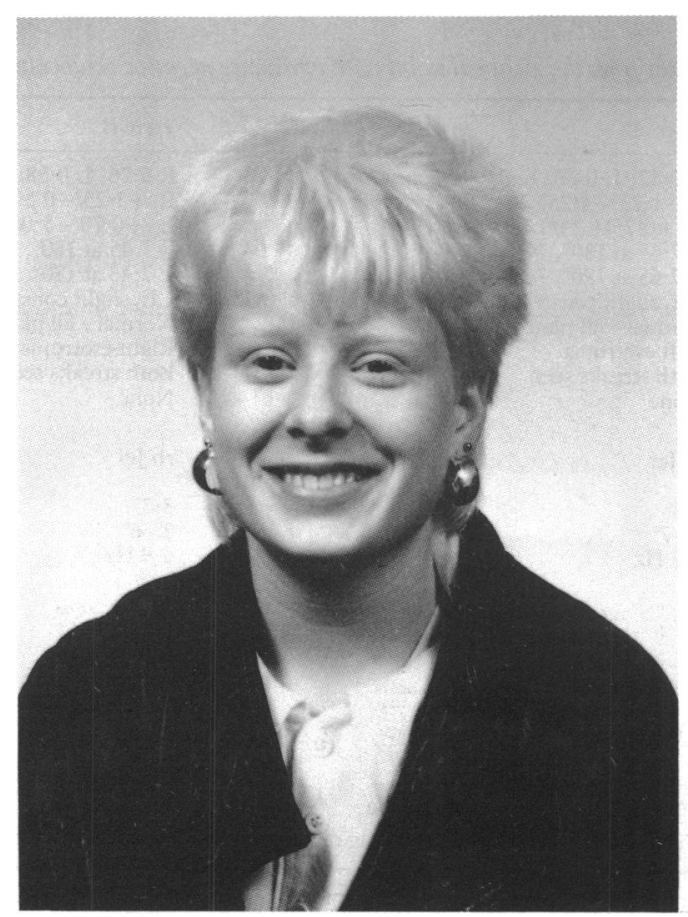

A consistent feature of TNOCA is congenital nystagmus $(\mathrm{CN})$. The bilateral, involuntary ocular oscillations are conjugate and occur predominantly in the horizontal plane, although torsional and occasionally vertical eye movements have been recorded..$^{9-13}$ As with other forms of $\mathrm{CN}$, much intra and intersubject variation in nystagmus characteristics is evident in TNOCA. In particular, the waveform shape, amplitude, and to a lesser extent, the frequency show great variability with gaze position.

In the tyrosinase negative (TN) albino population visual acuity ranges between $3 / 60$ and about $6 / 15$. Although these resolution levels are primarily dictated by the lack of a normally differentiated fovea, the presence of nystagmus is also responsible for some reduction in acuity..$^{14}$

To date there have been no quantitative accounts of the oculomotor behaviour of a pair of monozygote twins with TNOCA. The intention of this study was to examine the nature of the nystagmus and thereby provide some indication of the influence of the non-hereditary factors on the nystagmus oscillations.

\section{Patients and methods}

The female twins were born on 21 February 1971 and were the youngest of 10 children. TNOCA was diagnosed not long after birth and the twins were 16 years old at the time of the study (Fig 1). An older brother also manifested this condition.

Monozygosity was confirmed by the Manchester Regional Genetic Service which per-

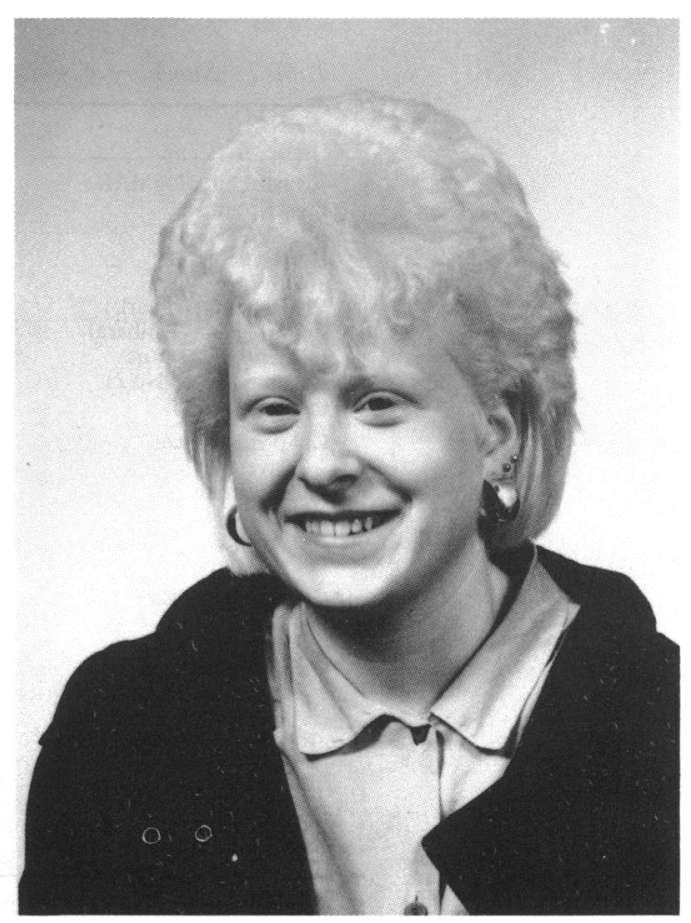

\author{
Ar R V Abadi \\ Accepted for pu
8 October 1993
}


formed a DNA fingerprint test. In this procedure DNA from blood samples was analysed with minisatellite probe 6.3. The results showed these twins had 19 shared and no unique bands.

Clinical appearance indicated that the twins were tyrosinase negative oculocutaneous albinos because they had white hair, pale pink skin devoid of freckles, light blue irides which iris transilluminated and hypopigmented fundi without macular pigment. ${ }^{1-616-18} \mathrm{~A}$ hair bulb incubation test confirmed their tyrosinase negative status. ${ }^{19}$

A full clinical investigation was carried out on the twins. This included refraction, keratometry (Bausch and Lomb), kinetic perimetry (Aimarkkinetic), colour vision (Ishihara plates), ophthalmoscopy, and fundus photography (Canon CR3 camera). Binocular and monocular visual acuities were measured with a high contrast $(90 \%)$ Bailey-Lovie chart located in the primary position. Visual acuities were recorded as the logarithm of the minimum angle of resolution $(\log M A R)$. The state of binocularity was examined by using different levels of dissociation: cover test, Maddox rod, and Bagolini lenses. Near stereo visual acuity (Institute for Perception TNO and Titmus tests) was also measured.

Binocular horizontal eye movements were recorded using infrared oculography (resolution 6 minutes of arc, bandwidth $70 \mathrm{~Hz}$ ) and electrooculography (resolution $\mathbf{3 0}$ minutes of arc, band width $23 \mathrm{~Hz}$ ). The infrared oculography was used to record eye movements within $\pm 20^{\circ}$ of the primary position and electro-oculography was used for gaze angles between $\pm 20^{\circ}$ and $\pm 40^{\circ}$. Several factors, such as fixation attempt and emotional state, have been found to affect the nystagmus characteristics. ${ }^{120}$ To minimise these variations, eye movement recordings were only commenced after a number of trial runs during which the twins familiarised themselves with the experimental procedure. In addition, the recordings were repeated on several separate occasions.

Eye position data were stored on a frequency modulated tape recorder and then digitised to 8 bit accuracy at $500 \mathrm{~Hz}$. The slow phases of each nystagmus cycle were sampled at $250 \mathrm{~Hz}$ then digitally filtered with a non-recursive quadratic filter $(-3 \mathrm{~dB}$ at $23 \mathrm{~Hz})$. In order to avoid the inclusion of any fast phases in this analysis, all fast phase data from $8 \mathrm{~ms}$ before to $8 \mathrm{~ms}$ after the point at which the saccadic velocity reached 40 degrees/second, were eliminated. Velocities derived from a two point central difference algorithm were then sampled at $12.5 \mathrm{~ms}$ intervals along the slow phase.

Head position was monitored with a light weight helmet strapped to the patient's head and recorded simultaneously during each visual acuity assessment.

Visual stimuli were presented on a hemicylindrical, matt white screen (radius of curvature $1.22 \mathrm{~m}$ ) which subtended $172^{\circ}$ horizontally and $50^{\circ}$ vertically. The patients were seated $1.3 \mathrm{~m}$ from the centre of the screen and head movements were minimised using a chin rest and forehead restraint. The stimuli consisted of a projected $0.5^{\circ}$ circular spot of light.

\section{Results}

A summary of the results of the clinical investigations is given in Table 1. The twins had several common features such as marked iris transillumination, normal colour vision, similar visual fields, and a lack of stereopsis. Fundus photography revealed that both twins had a complete lack of pigment in the retinal pigment epithelium thus the choroidal vasculature was easily visible. In addition, foveal reflexes could not be located and a lack of normal foveal differentiation was confirmed by monochromatic fundus photography, as neither twin had macular pigment. ${ }^{17} 18$

On the other hand, while their refractive errors were similar to those commonly found in albino populations, ${ }^{21-23}$ twin A exhibited a greater amount of corneal astigmatism than her sister.

On primary gaze both twins exhibited an esotropia as well as displaying conjugate,

Table 1 Summary of clinical data from the identical twins with tyrosinase negative oculocutaneous albinism

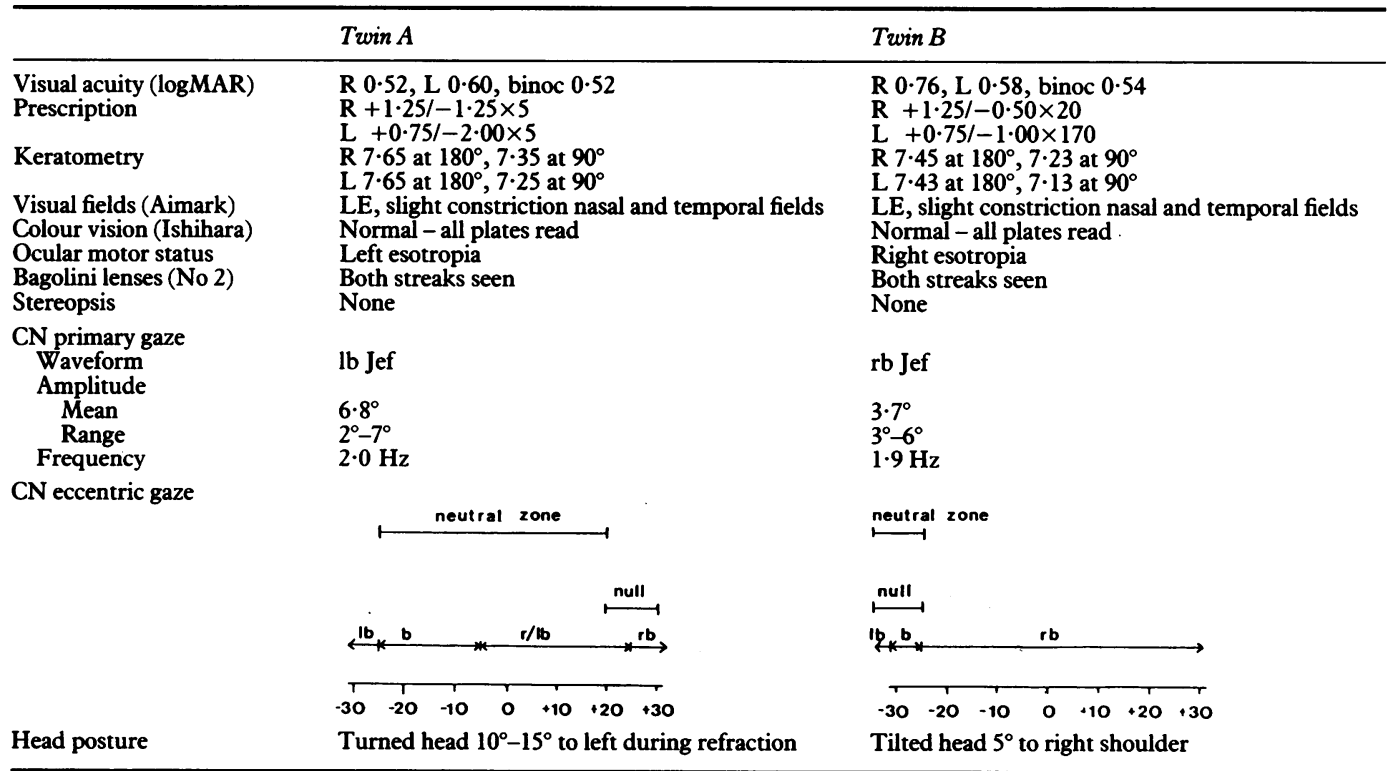


Figure 2 Infrared reflection oculographic recordings from the right eye of each albino twin, indicating the oscillation exhibited in five different gaze positions: central gaze $\left(0^{\circ}\right)$, left gaze $\left(-10^{\circ}\right.$, $-20^{\circ}$ ), and right gaze $\left(+10^{\circ},+20^{\circ}\right)$. In the primary position both twins demonstrated a jerk with extended foveation waveform, although the fast phases were in opposite directions: twin $A$ had a left beating nystagmus while twin $B$ had a right beating nystagmus.

$$
\text { 作 }
$$

bilateral, horizontal $\mathrm{CN}$. Figure 2 illustrates the oscillations recorded from the right eye of each twin during binocular fixation at five different gaze positions: $0^{\circ}, \pm 10^{\circ}, \pm 20^{\circ}$. In primary gaze both girls demonstrated a jerk with extended foveation (Jef) waveform, although the fast phases were in opposite directions; twin $\mathrm{A}$ had a left beating $\mathrm{CN}$ while twin $\mathrm{B}$ had a right beating CN.

Computer analysis of a 10 second period of primary gaze revealed that the twins' nystagmus frequencies were very similar $(1.9 \mathrm{~Hz}: 2.0 \mathrm{~Hz})$ whereas the amplitudes differed markedly: twin A had a larger oscillation (mean amplitude $6 \cdot 8^{\circ}$ ) and a greater range $\left(2-7^{\circ}\right)$ than twin $B$ who had smaller (mean amplitude $3.7^{\circ}$ ) and narrower range of $\left(3-6^{\circ}\right)$ eye movements. Although both twins had similar Jef waveforms, their oscillations were not identical as the foveation periods (defined as the percentage time that the $\mathrm{CN}$ slow phase velocity was less than or equal to 10 degrees/second) were of much longer duration in twin B. This is illustrated in Figure 3 where histograms indicating the percentage distribution of velocities which make up the $\mathrm{CN}$ slow phases over a period of 10 seconds are shown for each twin. This greater foveation did not however appear to be associated with improved visual capabilities because the twins had more or less equal binocular visual acuities when measured with a high contrast (90\%) Bailey-Lovie chart $(0.52$ and $0.54 \log$ MAR for twin $\mathrm{A}$ and $\mathrm{B}$ respectively).

The $\mathrm{CN}$ characteristics manifested in eccentric gaze, which are schematically represented at the bottom of Table 1, also differed for each twin. Twin B had a Jef oscillation in most positions of gaze, while twin A demonstrated far greater waveform variability including bidirectional waveforms between $5^{\circ}$ and $25^{\circ}$ left gaze and dual jerk oscillations beyond $25^{\circ}$ right gaze. The null zones were in opposite directions and the neutral zones were dissimilar. Twin A had a very broad neutral zone stretching from $+20^{\circ}$ to $-25^{\circ}$,

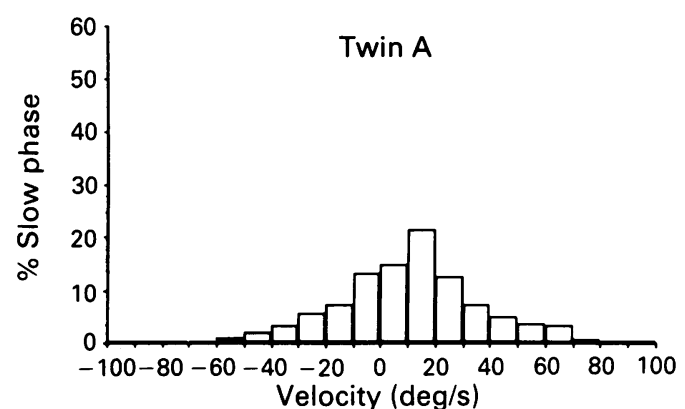

whereas twin B had a relatively narrow neutral zone which covered just $5^{\circ}$ either side of $-30^{\circ}$. During visual acuity assessment twin $A$ adopted a left head turn of about $10^{\circ}$ to $15^{\circ}$. The reason for adopting this strategy remains unclear as there is no obvious corresponding null zone at $+10^{\circ}$ to $+15^{\circ}$, although the $\mathrm{CN}$ did appear to be more regular and have slightly longer foveation times at these gaze angles in comparison with primary gaze. Alternatively twin A may have turned her head for reasons unrelated to vision. ${ }^{24}$

\section{Discussion}

The aim of this study was to investigate the ocular motor characteristics of identical twins with TNOCA in an attempt to assess the relative influences of genetic and environmental factors on $\mathrm{CN}$. Since monozygote twins have identical genotypes any differences between the two sisters must have arisen from other sources.

In agreement with a previous study ${ }^{25}$ which examined the eye movement characteristics of identical twins with congenital idiopathic nystagmus, this investigation found considerable ocular motor dissimilarity. The oscillations in primary gaze were of the same waveform type but were otherwise unalike and the variations in $\mathrm{CN}$ parameters with gaze angle were different. In fact, with respect to eye movements, these twins seemed no more alike than two unrelated TN albinos. If genetic background was of primary importance in determining the nature of the congenital ocular oscillations one would anticipate much greater correlation. Since the involuntary eye movements were not identical one must assume that environmental factors had a marked influence on the $\mathrm{CN}$ characteristics. Several studies have indicated that $\mathrm{CN}$ is not consistent in an individual and that various factors, including fixation attempt, convergencé, and emotional state can influence the nystagmus characteristics. Our repeated eye movement recordings in- 
dicated that, while the $\mathrm{CN}$ amplitude did vary, the frequency, waveform shape, and beat direction remained relatively invariant. Thus small individual variations cannot fully account for the differences in the twins' oscillations.

As part of a retrospective study based on eye movement records collected over 20 years Dell'Osso $^{26}$ looked at the relative incidence of each $\mathrm{CN}$ waveform or combination of waveforms in a population of 100 individuals. From these data he argued that since various family groups with $\mathrm{CN}$ (including a pair of monozygotic twins) displayed higher than expected probabilities of similar waveforms, heredity played a significant role in determining nystagmus characteristics. However, no mention was made of the similarities or differences in $\mathrm{CN}$ parameters such as amplitude or foveation time between family members. Thus two related individuals may have had the same underlying waveforms yet exhibited very different involuntary oscillations. It may well be that heredity determines the basic $\mathrm{CN}$ waveform in each individual, but environmental factors influence the features such as amplitude, frequency, beat direction, and foveation time or the manner in which combinations of waveforms are interrelated with respect to gaze angle.

There is little doubt that a greater understanding of the characteristics of human albinism could be gained by carrying out a longitudinal study of the type recently reported concerning visual evoked potentials. ${ }^{27}$ Ideally the study would start at the subjects' birth and examine not only the nature of $\mathrm{CN}$ in infancy ${ }^{28}$ but also the development of other ocular features such as refractive error.$^{29}$ It would be particularly informative if infant monozygotic twins with albinism could be found so that the onset of differences in nystagmus characteristics could be carefully examined. Since only one in 240 births produces identical twins, the likelihood of encountering such infants who also have oculocutaneous albinism is extremely low (about 1 in 4.8 million). There are probably only 15 such pairs living in the United Kingdom at any given time.

1 Witkop CJ. Depigmentations of the general and oral tissues and their genetic foundations. Ala 7 Med Sci 1979; 16: $331-43$.
2 O'Donnell FE, Green WR. The eye in albinism. In: Duane TD, ed. Clinical ophthalmology 4. New York: Harper and TD, ed. Clinical

3 Witkop CJ, Quevedo WC, Fitzpatrick TB. Albinism and other disorders of pigment metabolism. In: Stanbury JB, Wyngaarden JB, Frederickson DS, Goldstein JL, Brown MS, eds. The metabolic basis of inherited disease. 5 th ed. New York: McGraw-Hill, 1983: 301-46.

4 Kinnear PE, Jay B, Witkop CJ. Albinism. Surv Ophthalmol 1985; 30: 75-101.

5 Van Dorp DB. Shades of grey in human albinism. Amersfoot: Holland Ophthalmic Publishing Centre, 1985: 1-173.

6 Abadi RV, Pascal E. The recognition and management of albinism. Ophthalmol Physiol Opt 1989; 9: 3-15.

7 Witkop CJ, White JG, King RA. Oculocutaneous albinism. In: Nyhan WL, ed. Heritable disorders of amino acid metabolism. New York: J Wiley, 1974: 177-261

8 Jay B, Witkop CJ, King RA. Albinism in England. Birth Defects 1982; 18: 319-25.

9 Apkarian P, Spekreijse H, Collewijn H. Oculomotor behaviour in human albinos. Doc Ophthalmol Proc Series 1983; 37: 361-72.

10 St John R, Fisk JD, Timney B, Goodale MA. Eye movements of human albinos. Am $\mathcal{F}$ Optom Physiol Opt 1984; 61 : 377-85.

Collewijn H, Apkarian P, Spekreijse H. The oculomotor behaviour of human albinos. Brain 1985; 108: 1-28.

12 Abadi RV, Dickinson CM. Waveform characteristics in congenital nystagmus. Doc Ophthalmol 1986; 64: 153-67.

13 Abadi RV, Pascal E, Whittle J, Worfolk R. Retinal fixation behaviour in human albinos. Optom Vision Sci 1989; 66:

14 Abadi RV, Worfolk R. Retinal slip velocities in congenital nystagmus. Vision Res 1989; 29: 195-205.

15 Abadi RV, Pascal E. Visual resolution limits in human albinism. Vision Res 1991; 31: 1445-7.

16 Kriss A, Russell-Eggitt I, Harris CM, Lloyd IC, Taylor D. Aspects of albinism. Ophthalmic Paediat Genet 1992; 13: 89-100.

17 Abadi RV, Dickinson CM. Monochromatic fundus photography of human albinos. Arch Ophthalmol 1983; 101: 1706-11.

18 Abadi RV, Cox M. The distribution of macular pigment in human albinos. Invest Ophthalmol Vis Sci 1992; 33: 494-7.

19 Kugelman TP, Van Scott EJ. Tyrosinase activity in melanocytes of human albinos. F Invest Dermatol 1961; 37: $73-6$.

20 Abadi RV, Dickinson CM, Pascal E, Whittle J, Worfolk R. Sensory and motor aspects of congenital nystagmus. In: Schmid R, Zambarbien D, eds. Oculomotor control and cognitive processes. North-Holland: Elsevier Science, 1991: $249-62$.

21 Fonda G, Thomas H, Gore GV. Educational and vocational placement and low vision corrections in albinism. Sight Sav Rev 1971; 41: 29-36.

22 Taylor WOG. Visual disabilities of oculocutaneous albinism and their alleviation. Trans Ophthalmol Soc UK 1978; 98: 423-45.

23 Dickinson CM, Abadi RV. Corneal topography of humans with congenital nystagmus. Ophthalmol Physiol Opt 1984; 4: 3-13.

24 Abadi RV, Whittle J. The nature of head postures in congenital nystagmus. Arch Ophthalmol 1991; 109: 216-20.

25 Abadi RV, Dickinson CM, Lomas MS, Ackerley R. Congenital nystagmus in identical twins. Brf Ophthalmol 1983; Genital nys $693-5$.

26 Dell'Osso L. Congenital, latent and manifest latent nystagmus - similarities, differences and relation to strabismus. Fpn f Ophthalmol 1985; 29: 351-68.

27 Apkarian P, Tijssen R. Detection and maturation of VEP albino asymmetry: an overview and a longitudinal study from birth to 54 weeks. Brain Res 1992; 49: 57-67.

28 Casteels I, Harris CM, Shawkat F, Taylor D. Nystagmus in infancy. Brf Ophthalmol 1992; 76: 434-7.

29 Abadi RV, Dickinson CM, Pascal E, Papas E. Retinal image quality in albinos. Ophthalmic Paediat Genet 1990; 11: qui-7. 